QUADERNS DE FILOSOFIA VOL. VII NÚM. I (2020): 33-43

eISSN: 234I-3042 DOI: I 0.7203/QFIA. 7.I.I 6490

Tobies Grimaltos \& Carlos J. Moya

Universitat de València

\title{
A modest argument against scepticism
}

Received: 09.1.2020 / Accepted: 25.5.2020

Abstract: In this paper we don't intend to show, against the sceptic, that most of our everyday beliefs about the external world are cases of knowledge. What we do try to show is that it is more rational to hold that most of such beliefs are actually cases of knowledge than to deny them this status, as the external world sceptic does. In some sense, our point of view is the opposite of Hume's, who held that reason clearly favours scepticism about the independent existence of an external world rather than common sense belief in such an independent existence. In arguing for the superior rationality of this common sense, Moorean view, we also take a fallibilist conception of knowledge to be rationally preferable to an infallibilist view of it.

Keywords: Scepticism, argument from knowledge, common sense, brains-in-a-vat, Moore, Hume, fallibilism.

\section{INTRODUCTION}

$\mathrm{M}$ ODERN SCEPTICISM about our knowledge of the external world finds a paradigmatic expression in the arguments put forward by Descartes in the first of his Meditations. Putnam's (198I) thought experiment of brains in vats (BIVs, for short) is a contemporary version of Descartes's argument of the Evil Genius. The argument is partly addressed to those who, by sharing the materialist intuition that thought requires a material basis, find the idea of a purely unembodied mind, which is assumed in the Cartesian argument, scarcely intelligible. As is well known, Putnam (I98 I, 5-6) asks us to imagine the possibility that our brain had been taken out of our skull by a nefarious neurosurgeon, placed in a vat with nutrients and connected to a super- 
powerful computer, which, by means of electro-chemical signals, induces in it experiences of all sorts, indistinguishable to us from those that we would have if we were normal corporeal beings ${ }^{1}$. From this moment onwards, a large part of our beliefs about the world would be false. ${ }^{2}$ The bizarre character of this story notwithstanding, the sceptic's insidious question is how we know that it is false. And if we cannot give a satisfactory response to this question, if we cannot definitively rule out that possibility, it seems that those of our beliefs whose truth is incompatible with it are not sufficiently justified, so that they do not really amount to knowledge. Beliefs affected by this sceptical challenge include paradigmatically our everyday beliefs about the external world. We believe that we have hands, and that there exist houses, clouds and trees, but we do not know these things. Consider that any sensory experience that we could adduce in favour of our condition of corporeal beings that actually interact with the world is compatible with our being BIVs.

There have been several attempts to defeat arguments of this kind. Recent proposals can be divided into several groups: some of them rest on an externalist conception of meaning and of the intentional content of thoughts (e.g. PUtNAM I98 I and Wright I992); others advert to a contextualist conception of the truth conditions of knowledge attributions (e.g. DeRose 1995); still others resort to a denial of the Principle of Closure of Knowledge (e.g. DrETSKE I97I and NozICK 198I); and we can also mention those that fall under the labels "Explanationism" or "Abductivism" (BEEBE 2009 and forthcoming, Huemer 2016). Although the discussion about these anti-sceptical strategies is still going on, it is rather hard, in view of the current state of the debates, to be optimistic concerning the real chances of a clear defeat of scepticism.

In this paper, our aim will be more limited. We will not try to show that the sceptical hypotheses, and especially the hypothesis of brains in a vat, are false. And neither will we try to prove that most of our everyday beliefs about the external world are cases of knowledge. What we intend to defend is something more modest, namely, that it is more rational to hold that most of our spontaneous beliefs about the world are actually cases of knowledge than to deny them this status, as the sceptic does. ${ }^{3}$ In some sense, our point of view

${ }^{1}$ Bibliography about Putnam's argument is very extensive. Two detailed (though opposite) assessments of this argument can be found in Grimaltos (2003) and Pérez Otero (2012).

${ }^{2}$ If, due to Putnam's semantic externalism, it is not clear whether these beliefs would be false, there are other formulations of the BIV's hypothesis, previous to Putnam's, which clearly entail the falsity of a large part of our beliefs about the word. See, for instance, Pollock (I97I) or Harman (1974). In Pollock (1986) there is also a presentation of the BIV hypothesis with this implication.

${ }^{3}$ To the extent that explanationist responses hold "that our common sense beliefs about the external world can be rationally preferred to skeptical hypotheses" (BEEBE, forthcoming,1), our own proposal is close to them. However, our reasons in favor of that statement are different. Ex- 
is the opposite of Hume's, who held that reason clearly favours scepticism about the independent existence of an external world, and that only instinct or irrational faith ("the infallible and irresistible instinct of nature") supports the anti-sceptical, common sense belief in such an independent existence (cf. Hume $1777 / 1975$, sect. 12). We will hold instead that reason is on the side of common sense.

\section{i. Preliminary Remarks}

Let us start with some preliminary remarks. At the background of the way of reasoning which uses this kind of sceptical strategy there is an infallibilist conception of knowledge. As David Lewis says:

If you claim that $S$ knows that $P$, and yet you grant that $S$ cannot eliminate a certain possibility in which not- $P$, it certainly seems as if you have granted that $S$ does not after all know that $P$. To speak of fallible knowledge, of knowledge despite uneliminated possibilities of error, just sounds contradictory. (LewIs I996, 549)

According to infallibilism, the idea is, then, that in order to know that $P$ you have to be able to eliminate any possibility whatsoever in which not- $P$. And that means that your evidence in favour of $P$ has to be incompatible with not- $P$. Since empirical knowledge is knowledge mostly of contingent propositions, and contingent propositions ${ }^{4}$ are such that, no matter how good and how large your evidence $E$ in favour of a contingent proposition $P$ may be, it is always possible that $E$ be true and $P$ be false, the implication of this is, then, the impossibility of empirical knowledge and scepticism about the external world. Fallibilism, on the contrary, defends that it is possible for $S$ to know that $P$ even if the evidence she has is compatible with some possibilities in which not- $P^{5}$ That is to say, for the infallibilist any possibility of not- $P$, no matter how farfetched, is relevant for knowledge attributions. For the fallibil-

planationists defend the statement "on the grounds that the former provide better explanations of our sensory experiences than the later" (Ibid.). Instead, we do not rely on an inference to the best explanation in order to justify the superior rationality of common sense.

${ }^{4}$ With some special exceptions, such as necessary a posteriori propositions and the Cartesian Cogito.

${ }^{5} \mathrm{Or}$, as Stanley $(2005,127)$ characterizes fallibilism, "someone can know that $\mathrm{p}$, even though their evidence for $\mathrm{p}$ is logically consistent with the truth of not-p". See also Dougherty and Rysiew (2009, 127) 
ist, however, only those possible worlds in which not- $P$ that are close to the actual world have to be taken into account for knowledge attributions. Hence, our contention that it is more rational to consider lots of our spontaneous beliefs as cases of knowledge than to deny them this status will also be a defence of fallibilism against infallibilism.

\section{TwO OPPOSED ARGUMENTS}

Let us now proceed to arguing for that contention.

We may represent the debate between the sceptic and (as we could call her opponent, in honour of Moore ${ }^{\natural}$ ) the Moorean by means of two opposed arguments. The sceptic argues as follows:

S:

1) I don't know that I am not a BIV.

2) If I don't know that I am not a BIV, I don't know that I have hands. Therefore,

3) I don't know that I have hands. ${ }^{7}$

DeRose (1995) has called this argument "the argument from ignorance". Obviously, the argument questions virtually all of our beliefs about the world, for there is nothing special to the belief that I have hands.

In opposition to the sceptic, the Moorean argues as follows:

M:

1) I know that I have hands.

2) If I know that I have hands, I know that I am not a BIV. Therefore,

3) I know that I am not a BIV.

$\mathrm{S}$ and $\mathrm{M}$ represent two ways of reasoning, characteristic of the sceptical attitude and of our anti-sceptical, common sense attitude, respectively. And they make clear the dialectic that arises between both attitudes, for, as we can see, $S$ leads to $\mathrm{M}$ and $\mathrm{M}$ leads to $\mathrm{S}$ through the negation of their respective conclusions.

${ }^{6}$ See Moore (1939).

${ }^{7}$ It is clear that, in order to be valid, the argument requires the Principle of Closure of Knowledge, according to which, if $S$ know that $p$ and knows that $p$ implies $q, S$ knows that $q$. This is why some responses to skepticism, such as Dretske's or Nozick's, referred to above, deny the validity of this principle.

${ }^{8}$ A good analysis of this argument is put forward in Pryor (2004). 
The negation of the conclusion of argument $S$ turns into the first premise of argument $\mathrm{M}$, and conversely, so that instability goes on indefinitely, not only between the sceptic and her opponent, but also, and especially, in ourselves, as soon as we become aware of the sceptical hypotheses. On the one hand, and with the obvious exception of the one-handed (or people with no hands), we are convinced that we have hands. On the other hand, given that a BIV does not have hands, and that, owing to the way in which the sceptical possibility that we are BIVs is formulated, it does not seem possible to exclude that we are such, we are led to accept the conclusion that we do not actually know that we have hands, no matter how firmly we believe it. But in seeing and feeling our hands, in touching other things with them, we again become convinced that we know we have hands, and we are thus led to the anti-sceptical conclusion. And the game continues again and again.

Is there some way of breaking this circle and showing that one of the arguments, and its conclusion, is preferable or superior to the other? In order to respond, we may ask what kind of support or basis, what type of considerations or evidence can the sceptic and the Moorean offer in favour of the first premise of their respective arguments (we will assume that the second premise is not problematic in either case). One way of finding this out would be to remove the epistemic operators ("know that...") from both arguments. In the case of $\mathrm{M}$, the result is:

M':

1) I have hands.

2) If I have hands, I am not a BIV. Therefore,

3) I am not a BIV.

What happens, though, with argument $S$ ? We cannot obtain in this case an argument parallel to the former, by going from "I don't know that I am not a BIV" to "I am a BIV", in order to have an argument in contraposition to M', which started with the negation of its conclusion:

*S':

1) I am a BIV.

2) If I am a BIV, I do not have hands. Therefore,

3) I do not have hands.

Premise 2 of ' ${ }^{*}$ ' is clearly true. But not even a sceptic would grant premise 1. In fact, to accept it would undermine her own sceptical commitment. And, more importantly, whereas we can validly deduce "I have hands", which is premise 1 of M', from "I know that I have hands", ' which is premise 1 of M, 
we cannot validly deduce premise 1 of * $S$," "I am a BIV", from premise 1 of $S$, "I don't know that I am not a BIV".

What would it mean to remove the epistemic operator in the case of S's premise 1, "I don't know that I am not a BIV"? One suggestion could be something like "I might be a BIV" or maybe better, "It is possible that I am a BIV". We could then use the latter as premise 1 of a new argument, which would take the following form:

$S^{\prime}:$

1) It is possible that I am a BIV.

2) If it is possible that I am a BIV, it is possible that I do not have hands. Therefore,

3) It is possible that I do not have hands.

The result is not fully satisfactory. Whereas M1 (premise 1 of argument $\mathrm{M}$, that is, "I know that I have hands") implies M'1 ("I have hands"), S1 ("I don't know that I am not a BIV") does not imply S'1 ("It is possible that I am a BIV"). $S 1$ may be true and $S^{\prime} 1$ may be false: it is compatible that I don't know that not- $p$ and that $p$ itself is not possible if, for instance, $p$ states an impossibility. Suppose for example that I don't know that the highest prime number does not exist; from this, it does not follow that it is possible that the highest prime number exists. This suggests that the possibility that appears in $S^{\prime}$ is epistemic, not objective, which means that the epistemic operators have not been actually removed, but have remained implicitly there. It seems that $S$ ' 1 should better be read as: "For all the information I have, it is possible that I am a BIV" or, "that I am a BIV is compatible with the evidence I have".

We can now compare the two first premises of $M^{\prime}$ and $S^{\prime}$ and see the support they offer to the first premises of the original arguments, $M$ and $S$ (as I have indicated, their respective second premises do not seem to be problematic). As a Moorean, I can offer, as a decisive support for M1 ("I know that I have hands"), a fact, the fact stated by M'1 ("I have hands"), namely, that I have hands, in favour of which I have lots of evidence. ${ }^{10}$ And with this decisive

${ }^{9}$ Since knowledge, as Mooreans and sceptics accept, is factive: if $S$ knows that $p$, then $p$.

${ }^{10} \mathrm{~A}$ big amount of experiences, indeed. And it is quite plausible, from different points of view, that they confer prima facie justification to the belief that I have hands. As Pryor writes, this "justification does not rest on any premises about Moore's [or our] experiences: whether they constitute perceptions, how reliable they are, or anything like that. It's in place so long as he merely has experiences that represent there to be hands. There are things Moore could learn that would undermine this justification. But it's not a condition for having it that he first have justification to believe those undermining hypotheses are false" (PrYOR 2004, 356). And the sceptical claim that our experiences are logically compatible with a far-fetched possibility can hardly undermine this prima facie justification. 
support, and given the conditional premise M2, which seems clearly correct, I can go from M1 to the anti-sceptical conclusion M3: "I know that I am not a BIV". Nevertheless, in favour of S1 ("I don't know that I am not a BIV"), I cannot avail myself, as a sceptic, of anything comparable to the fact that I have hands, which, as a Moorean, I can resort to in favour of M1. As a sceptic, I can only make use, in favour of S1, of a mere hypothesis or conjecture ("It is possible that I am a BIV" or "For all the information I have, it is possible that I am a BIV"), formed on the basis of a story such as that of brains in a vat (or the Evil Genius) and my apparent impossibility of showing that it is false, a conjecture in favour of which I do not have any evidence. ${ }^{11}$ And, leaving aside the conditional premise $S 2$, that conjecture is all that I can adduce as a support for the sceptical conclusion S3: "I don't know that I have hands". In view of this comparison, we can now see that the Moorean argument $\mathrm{M}$ has a more solid foundation than the sceptical argument $S$. Whereas $M$ rests on a fact, supported by lots of evidence, $S$ is supported by a mere conjecture, in favour of which there is no evidence; its only support is that, in a very strong, infallibilist sense, my evidence cannot rule out this possibility. That an evidence in favour of $p$ is in some way compatible with not- $p$, does not mean that it is not an evidence for $p$ or that it is also an evidence for not- $p$. It would then be irrational to opt for $S$ instead of $\mathrm{M}$. If we are to guide the formation of our beliefs in a reasonable way, it is clearly preferable for us to rely on what we take to be facts, if we can do it, than on what we take to be mere conjectures. Concerning rationality, $M$ and $S$ are not on the same level. $M$ is clearly superior to $S$.

\section{AN EXPECTED OBJeCtion}

The objection that we no doubt can expect against this point of view is that considering as a fact that $\mathrm{I}$ have hands is to beg the question against the sceptic, who will refuse to accept that this is a fact as long as it has not been demonstrated that her conjecture (or at least the story on which it rests) is false. Remember, however, that we did not intend to show that the sceptical conjecture, and the conclusion that the sceptic draws out of it, are false. What we have tried to establish is that, faced with the option between the sceptical and the Moorean pathways, it is more rational to choose the latter rather than the former. And the reason is that all our evidence favours the view that we have

${ }^{11}$ Of course we do not have evidence in Williamson's sense of this word, according to which only knowledge counts as evidence, but neither do we have it in an internalist sense (as in the case of Feldman and Conee's evidentialism or Pryor's dogmatism. Cf. Williamson 2000, Feldman and Conee 1985 and Pryor 2000). 
hands, for there is no plausible view of evidence on which I have evidence that I am a BIV. ${ }^{12}$ Instead, the only support that the sceptic can adduce in favour of her hypothesis is that those evidences are (logically) compatible with the possibility that we are BIVs. ${ }^{13}$ But, as we have said, that something is compatible with a certain possibility is no evidence for this possibility. In more formal terms: the fact that my evidence for $p$ is consistent with not- $p$ is no evidence in favor of not- $p$. Suppose that, during a trial on the robbery of a jewelry, a witness testifies that he saw the prosecuted person going out of of the jewelry with a gun in his hands. This is evidence that it was the prosecuted who did the robbery. Suppose now that the lawyer replies that it might be the case that there was a lookalike of the prosecuted and that it might be him, not the prosecuted, who went out of the jewelry. This hypothesis is not absurd or irrational, but the witness' testimony is not evidence for it. Rather, it is (fallible) evidence that it was the prosecuted who did the robbery. In a similar vein, that the skeptical hypothesis is not per se absurd or irrational does not mean that it is justified by any evidence, contrary to what happens with the belief that I have hands: all sorts of evidences support this belief, even if they do not establish it in a conclusive way (because it is not logically implied by them). And, in order to defend the rational superiority of the Moorean pathway over the sceptical one, it is not required that having hands is, at the end of the day and in the ultimate reality of things, a fact; it is enough that having hands is what, in our everyday life, we call a fact, and that the story of brains in vats (or of the Cartesian Evil Genius) is what we call a mere conjecture or maybe a mere fantasy. Certainly, including the sceptic, we would not call it a fact. Instead, evidence of several kinds, including sensory experience, allows us to consider that it is a fact that I have hands. To repeat, when the issue is to form and evaluate our beliefs about the world, it is a more rational procedure to rest on what we take to be facts than on what we take to be conjectures or fantasies. And it is a more sensible procedure to reject what we take to be a conjecture on the basis of what we take to be a fact, as the Moorean does, than to deny what we clearly take to be a fact on the basis of what we take to be a mere conjecture, as the sceptic does.

${ }^{12}$ If I have an experience like seeing my hands, this counts as an evidence for believing that I have hands, and not, in any case, as evidence in favor that I am a BIV. Because, either this experience is veridical, and then factive or, if it is not, and I am not aware of the existence of defeaters, I will take it as a token of a reliable type of process for justifiably believing that I have hands. Think that even the majority of reliabilists would accept that the BIV is justified (has evidence) in her ordinary "perceptual" beliefs. See Goldman (I988) and Comesaña (2010). From an internalist point of view, it is clear that such an experience counts as evidence.

${ }_{13}$ Or, according to Putnam's (198I) argument, not even that, since, according to him the BIVs hypothesis, understood in the sense that all of us have always been BIVs (not as the cas of being a recently-envated BIV), is not a logical possibility. 
The Moorean and the sceptical pathways are not on an equal footing from the point of view of their rational justification. From this point of view, there is no stalemate between them. It is, then, more rational to hold, with the Moorean, that our spontaneous beliefs about the world amount to knowledge than to follow the sceptic's steps and deny that epistemic value to them. And this is so even if, in the end, it turned out that we were brains in vats, for, unfortunately, rationality and truth do not always go together. 


\section{REFERENCES}

Beebe, J. R. 2009, “The Abductivist Reply to Skepticism”, Philosophy and Phenomenological Research 79: 605-36.

Beebe, J. R. Forthcoming, “Does Skepticism Presuppose Explanationism?” In Ted Poston and Kevin McCain (ed.), Best Explanations: New Essays on Inference to the Best Explanation, New York: Oxford University Press.

Comesaña, J. 20 io, "Evidentialist Reliabilism”, Noûs 44: 571-600.

DeRose, K. I995, "Solving the skeptical problem", Philosophical Review 104: 17-52.

Dougherty, T. and Rysiew, P. 2009, "Fallibilism, Epistemic Possibility, and Concessive Knowledge Attributions", Philosophy and Phenomenological Research 78: 123-32.

Dretske, F. I97I, "Conclusive Reasons", Australasian Journal of Philosophy 49: $1-22$.

Feldman, R. and Conee, E. I985, "Evidentialism", Philosophical Studies 48: $15-34$.

Goldman, A. I988, "Strong and Weak Justification", Philosophical Perspectives 2: 51-69.

Grimaltos, T. 2003, "Cerebros y escarabajos. Sobre el argumento antiescéptico de Putnam", Teorema XX/3: 21-40.

Harman, G. I974, Thought, Princeton: Princeton University Press

Huemer, M. 2016, "Serious theories and skeptical theories: Why you are probably not a brain in a vat", Philosophical Studies 173: 1031-52.

Hume, D. I777/I975, An Enquiry Concerning Human Understanding. In his Enquiries Concerning Human Understanding and Concerning the Principles of Morals, ed. L. A. Selby-Bigge and P. H. Nidditch, $3^{\text {rd }}$ edition. Oxford: Clarendon Press.

LEwIs, D. I996, "Elusive Knowledge”, Australasian Journal of Philosophy 74: 54967.

Moore, G. E. M. 1939, "Proof of an External World", Proceedings of the British Academy 25: 273-300.

Nozick, R. I98 I, Philosophical Explanations, Cambridge MA: Harvard University Press.

Pérez Otero, M. 2012, "La prueba de Putnam contra el escepticismo radical: Dos interpretaciones basadas en el autoconocimiento", Critica 44: 35-63.

Pollock, J. L. I97 I, Knowledge and Justification, Princeton: Princeton University Press.

Pollock, J. L. I987, Contemporary theories of Knowledge, London: Rowman and Littlefield. 
Pryor, J. 2000, "The Skeptic and the Dogmatic", Noûs 34.4: 517-49.

PrYOR, J. 2004, "What's Wrong with Moore's Argument?", Philosophical Issues 14: 349-78.

Putnam, H. I98 I, "Brains in a vat. In his Reason", Truth and History, 1-21. Cambridge: Cambridge University Press.

Stanley, J. 2005, "Fallibilism and Concessive Knowledge Attributions", Analysis 65: 126-31.

Williamson, T. 2000, Knowledge and its Limits, Oxford: Oxford University Press.

Wright, C. 1992, "On Putnam's proof that we are not brains-in-a-vat", Proceedings of the Aristotelian Society 92: 67-94. 